\title{
Farklı inkübasyon dönemlerine ve vermikompost uygulamalarına bağlı olarak toprakların bitki besin maddesi içeriklerindeki değişim
}

\section{Changes in plant nutrients contents of soils depending on different incubation periods and vermicompost applications}

\author{
Sahriye SÖNMEZ ${ }^{1 \oplus, \text { Nil ÖZEN² }}{ }^{-\infty}$ \\ ${ }^{1}$ Akdeniz Üniversitesi, Ziraat Fakültesi, Toprak Bilimi ve Bitki Besleme Bölümü, Antalya \\ ${ }^{2}$ Akdeniz Üniversitesi, Fen Bilimleri Enst., Toprak Bilimi ve Bitki Besleme ABD, Antalya \\ Sorumlu yazar (Corresponding author): S. Sönmez, e-posta (e-mail): ssonmez@akdeniz.edu.tr \\ Yazar(lar) e-posta (Author e-mail): nilozen@ hotmail.com
}

\section{MAKALE BİLGİSİ}

Alınış tarihi 12 Mart 2019

Düzeltilme tarihi 19 Nisan 2019

Kabul tarihi 26 Nisan 2019

\section{Anahtar Kelimeler:}

Alınabilir P

İnkübasyon

Mineralizasyon

Toplam N

Vermikompost

\begin{abstract}
ÖZ
Bu çalışmada; farklı inkübasyon sürelerinin ve artan düzeylerde yapılan vermikompost uygulamalarının, toprakların bitki besin maddesi içerikleri [toplam azot $(\mathrm{N})$, alınabilir fosfor $(\mathrm{P})$, değişebilir potasyum $(\mathrm{K})$, kalsiyum $(\mathrm{Ca})$ magnezyum $(\mathrm{Mg})$, alınabilir çinko $(\mathrm{Zn})$, demir $(\mathrm{Fe})$, mangan $(\mathrm{Mn})$ ve bakır $(\mathrm{Cu})]$ üzerine etkilerinin araștırılmas amaçlanmıştır. Bu amaçla, vermikompost 4 farklı dozda $\left(0,50,100\right.$ ve $\left.200 \mathrm{~kg} \mathrm{da}^{-1}\right)$ uygulanmış ve 0,30 ve 60 gün inkübasyona bırakılmıștır. Serada yürütülen bu çalıșma, tesadüf blokları deneme desenine göre 3 tekerrürlü olarak yürütülmüștür. İnkübasyon süreleri sonucunda alınan toprak örneklerinde toplam N, alınabilir $\mathrm{P}$, değișebilir $\mathrm{K}, \mathrm{Ca}$ $\mathrm{Mg}$ ve alınabilir $\mathrm{Fe}, \mathrm{Mn}, \mathrm{Zn}$ ve $\mathrm{Cu}$ analizleri yapılmıştır. Farklı inkübasyon sürelerinin toprakların toplam N, $\mathrm{Mg}$ ve alınabilir $\mathrm{Fe}, \mathrm{Mn}, \mathrm{Zn}$ ve $\mathrm{Cu}$ analizleri yapılmıştır. Farklı inkübasyon sürelerinin toprakların toplam $\mathrm{N}$,
alınabilir $\mathrm{P}$, değișebilir $\mathrm{K}, \mathrm{Ca}$, alınabilir $\mathrm{Zn}, \mathrm{Fe}, \mathrm{Mn}$ ve $\mathrm{Cu}$ içerikleri üzerine etkileri istatistiksel olarak \%0.1 düzeyde alınabilir $\mathrm{P}$, değişebilir $\mathrm{K}, \mathrm{Ca}$, alınabilir $\mathrm{Zn}, \mathrm{Fe}, \mathrm{Mn}$ ve $\mathrm{Cu}$ içerikleri üzerine etkileri istatistiksel olarak \%0.1 düzeyde
önemli bulunurken; toprakların değişebilir $\mathrm{Mg}$ içeriği üzerine inkübasyon sürelerinin etkisi istatistiksel olarak önemsiz bulunmuștur. İnkübasyon süresinin uzamasına (60. Güne doğru) bağlı olarak toprakların değișebilir K, Ca ve alınabilir $\mathrm{Mn}$ içeriklerinin azaldığı; toprakların alınabilir $\mathrm{P}, \mathrm{Zn}, \mathrm{Fe}$ ve $\mathrm{Cu}$ içeriklerinin 30.güne doğru azaldığ ancak 60. günde arttı̆̆ ; toprakların toplam N içeriğinin ise inkübasyon sürelerinin uzamasına bağlı olarak 30.gün toprakların toplam $\mathrm{N}$, alınabilir $\mathrm{P}$, değisebilir $\mathrm{K}$ icerikleri äzerine etkileri istatistiksel ola $\% 0.1$; al $\mathrm{Mn}$ içerikleri üzerine \%1, değişebilir Ca içeriği üzerine etkilerinin istatistiksel olarak $\% 5$ düzeyinde önemli olduğu belirlenmiștir. Artan düzeylerde yapılan vermikompost uygulamalarının değişebilir $\mathrm{Mg}$, alınabilir $\mathrm{Fe}, \mathrm{Cu}$ içerikleri üzerine etkisi ise istatistiksel olarak önemsiz bulunmuştur. Artan vermikompost uygulama dozuna bağlı olarak toprakların alınabilir $\mathrm{P}, \mathrm{Zn}, \mathrm{Mn}$ ve değișebilir $\mathrm{Mg}$ içeriklerinin genel olarak arttığı; toplam $\mathrm{N}$ ve değișebilir $\mathrm{Ca}$ içeriklerinin azaldığı belirlenmiștir. Sonuç olarak farklı inkübasyon dönemlerine ve artan vermikompost uygulama dozlarına bağl olarak toprakların bitki bro österdiği; inkübasyon süresinin uzamasına bağlı olarak bitki besin elementi içeriklerinin genel olarak azaldığı, artan vermikompost uygulamalarına bağlı olarak ise arttığı belirlenmiştir.
\end{abstract}

\section{ARTICLE INFO}

Received 12 March 2019

Received in revised form 19 April 2019 Accepted 26 April 2019

Keywords:

Available P

Incubation

Mineralization

Total N

Vermicompost

\begin{abstract}
The aim of this study was to investigate the effects of different incubation times and increasing levels of vermicompost applications on the nutrients contents (total $\mathrm{N}$, available $\mathrm{P}$, exchangeable $\mathrm{K}$, ca and $\mathrm{Mg}$, available $\mathrm{Fe}$, $\mathrm{Mn}, \mathrm{Zn}$ and $\mathrm{Cu}$ ) of soils. For this purpose, vermicompost were applied at 4 doses $(0,50,100$ and $200 \mathrm{~kg}$ da-1), and left to the incubation for 0,30 and 60 days. This study was carried out in 3 replications according to randomized block experiment design in greenhouse conditions. Soil samples were taken at the end of incubation times, and analyzed for total $\mathrm{N}$, available $\mathrm{P}$, exchangeable $\mathrm{K}, \mathrm{Ca}$ and $\mathrm{Mg}$, available $\mathrm{Fe}, \mathrm{Mn}, \mathrm{Zn}$ and $\mathrm{Cu}$. While the effects of analyzed for total $\mathrm{N}$, available $\mathrm{P}$, exchangeable $\mathrm{K}$, $\mathrm{Ca}$ and $\mathrm{Mg}$, available $\mathrm{Fe}, \mathrm{Mn}, \mathrm{Zn}$ and $\mathrm{Cu}$. While the effects of different incubation times on the total $\mathrm{N}$, available $\mathrm{P}$, exchangeable $\mathrm{K}, \mathrm{Ca}$, available $\mathrm{Zn}, \mathrm{Fe}, \mathrm{Mn}$ and $\mathrm{Cu}$ contents of
the soils were statistically significant at $0.1 \%$; the exchangeable $\mathrm{Mg}$ content of soils was statistically insignificant. As a result of the experiment; depending on the prolongation of the incubation times (towards the 60th day), the exchangeable $\mathrm{K}, \mathrm{Ca}$ and available $\mathrm{Mn}$ contents of soils may be reduced; the available $\mathrm{P}, \mathrm{Zn}, \mathrm{Fe}$ and $\mathrm{Cu}$ contents of the soils decreased to 30th day but increased on the 60th day; It was determined that the total $\mathrm{N}$ content of the soils increased until 30th day due to prolongation of incubation times but decreased at 60th day. It was determined that the effects of increasing vermicompost applications were found to be statistically significant at $0.1 \%$ on the total $\mathrm{N}$, the effects of increasing vermicompost applications were found to be statistically significant at $0.1 \%$ on the total $\mathrm{N}$, statistically significant on exchangeable $\mathrm{Mg}$, available $\mathrm{Fe}$ and $\mathrm{Cu}$ contents of soils. Depending on increasing vermicompost applications, it was determined that the available, $\mathrm{P}, \mathrm{Zn}, \mathrm{Mn}$ and exchangeable $\mathrm{Mg}$ contents of the soils increased, and the contents of total $\mathrm{N}$ and exchangeable $\mathrm{Ca}$ decreased. As a result, depending on the different incubation times and increased vermicompost applications, the nutrients contents of the soils were different from each other. The contents of the plant nutrients were generally decreased with the prolongation of the incubation times, and increased with increasing vermicompost applications.
\end{abstract}




\section{Giriş}

Ülkemizde 2018 yılı toplam tarım alanı 37.817 bin hektardır. Mevcut olan tarım alanlarımızın toprak özelliklerinin iyileştirilmesi ve yetiştirilecek olan bitkilerden daha iyi verim alınması için toprakların bitki besin element içeriklerinin optimum tutulmas1 veya arttırılmas1 gerekmektedir.

Toprağa organik materyal ilavesiyle toprağın kendi bünyesinde bulunan organik madde miktarı artmaktadır, buna bağlı olarak da toprakların agregat stabilitesi, hava-su dengesi, erozyona karşı direnci ve topraklardaki bitki besin elementlerinin alımı olumlu yönde etkilenerek artmaktadır. Organik materyallerin; toprağa daha sikı tutunarak kimyasal gübrelere göre yıkanma sonucunda azot kaybını en aza düşürdüğü ve çevre kirliliğini minimum seviyeye indirdiği bilinmektedir (Jakse ve Mihelic 1999).

Tarımsal girdilerden "gübre" denilince akla genellikle kimyasal gübreler gelmektedir. Ancak organik gübrelerin kullanılması ve üretilmesi de günden güne artış göstermektedir. Son yıllarda çok sık kullanılan organik gübrelerden birisi de vermikomposttur. Vermikompost yapısal olarak incelendiğinde; su tutma kapasitesinin ve içeriğindeki mikrobiyal aktivitenin yüksek olduğu, gözenekli bir yapıya sahip olduğu ve torfa benzer, ince dokulu bir materyal olduğu görülmektedir (Ansari 2008; Garg ve ark. 2010). Ancak kullanılacak organik materyallerin özellikle $\mathrm{N}$ mineralizasyon düzeylerinin bilinmesi, toprakların bitki besin element içeriği, bitki yetiştiriciliğinde bitkinin verim ve kalitesi bakımından önem taşımaktadır.

Topraklara yapılan organik uygulamaların mineralizasyonunda inkübasyon süresinin önemli olduğu bazı araştırmacılar tarafindan da ifade edilmiştir (Zengin ve ark. 1999, Eczacıbaşı ve Arcak 1999). Organik uygulamaların topraklardaki $\mathrm{N}$ ve $\mathrm{P}$ mineralizasyon oranlarına etkilerinin ortaya çıkmasında inkübasyon süresinin oldukça önemli olduğu bilinmektedir. Bellitürk ve Sağlam (2005) 14 gün inkübasyona bırakılan toprakların, mineralizasyon oranları ile kireç içerikleri arasında artan oranda ilişkiler olduğunu belirlemişlerdir. Kara (1997), 6-7 haftalık inkübasyon sonrası toprakların mineralize olabilir $\mathrm{N}$ içeriklerinin maksimuma ulaştığını ve inkübasyon süresi arttıkça toprakların organik maddelerinin parçalanma oranının azaldığını bildirmişlerdir (Wadman ve De Haan 1997). Çok sayıda mineral toprak örnekleri üzerinde çalışan Pritchettk ve ark. (1959), iki haftalık inkübasyon sonunda toprakların organik madde ile nitrat içerikleri arasında istatistiki olarak önemsiz ilișkiler bulurken; toplam $\mathrm{N}$ ile nitrat içerikleri arasında çok önemli istatistiki ilişkiler bulunduğunu tespit etmişlerdir.

$\mathrm{Bu}$ çalışma ile farklı inkübasyon sürelerinin ve artan düzeylerde yapılan vermikompost uygulamalarının, toprakların bitki besin maddesi içerikleri (toplam $\mathrm{N}$, alınabilir $\mathrm{P}$, değişebilir $\mathrm{K}, \mathrm{Ca}, \mathrm{Mg}$, alınabilir $\mathrm{Zn}, \mathrm{Fe}, \mathrm{Mn}$ ve $\mathrm{Cu}$ ) üzerine etkilerinin araştırılması amaçlanmıştır.

\section{Materyal ve Yöntem}

Deneme, Akdeniz Üniversitesi Tohumculuk ve Tarımsal Biyoteknoloji Araştırma ve Uygulama Merkezi'ne ait serada yürütülmüştür. Farklı inkübasyon dönemlerinde uygulanan vermikompostun toprağın bitki besin element içerikleri üzerine etkilerini belirlemek için yürütülen deneme, 4 l'lik saksılarda tesadüf blokları deneme desenine göre 3 tekerrürlü olarak gerçekleştirilmiştir. Denemede; vermikompost 4 farklı dozda ( 0 , 50,100 ve $200 \mathrm{~kg}$ da) uygulanmış ve 0,30 ve 60 gün inkübasyona bırakılmıştır. Deneme; 4 farklı uygulama dozu, 3 farklı inkübasyon süresi ve 3 tekerrürlü olmak üzere 36 saksıdan oluşmuştur.

Denemede kullanılan vermikompostun; $\mathrm{pH}$ ve $\mathrm{EC}$ düzeyleri 1:2.5 oranında toprak-su karışımında (Jackson 1967), toplam N Kjeldahl yöntemine göre (Kacar ve İnal 2010); P, K, Ca, Mg, $\mathrm{Fe}, \mathrm{Mn}, \mathrm{Zn}$ ve $\mathrm{Cu}$ içerikleri yaş yakma sonucu elde edilen süzükte (Kacar ve İnal 2010) ICP cihazında belirlenmiş ve sonuçlar Çizelge 1'de verilmiştir.

Çizelge 1. Vermikompostun kimyasal özellikleri.

Table 1. Chemical properties of vermicompost.

\begin{tabular}{lclc}
\hline Parametreler & Sonuçlar & Parametreler & Sonuçlar \\
\hline $\mathrm{pH}$ & 7.46 & $\mathrm{Ca}, \mathrm{ppm}$ & 5378 \\
$\mathrm{EC}\left(\mathrm{dS} \mathrm{m}^{-1}\right)$ & 6.53 & $\mathrm{Mg}, \mathrm{ppm}$ & 1193 \\
Toplam N, \% & 1.103 & $\mathrm{Mn}, \mathrm{ppm}$ & 3.534 \\
$\mathrm{P}, \mathrm{ppm}$ & 3701 & $\mathrm{Zn}, \mathrm{ppm}$ & 7.573 \\
$\mathrm{~K}, \mathrm{ppm}$ & 5905 & $\mathrm{Cu}, \mathrm{ppm}$ & 2.199 \\
$\mathrm{Na}, \mathrm{ppm}$ & 1047 & $\mathrm{Fe}, \mathrm{ppm}$ & 34.75 \\
\hline
\end{tabular}

İnkübasyon süreleri sonunda saksılardan alınan toprak örnekleri, kurutulup 2 mm'lik elekten elenerek analize hazır hale getirilmiştir. Araştırmada kullanılan toprağın bazı fiziksel ve kimyasal analizleri yapılmıştır. Denemede kullanılan toprakta ve inkübasyon süreleri sonunda alınan toprak örneklerinde; toplam N Kjeldahl yöntemine göre (Kacar 2014), alınabilir P Olsen yöntemine göre (Olsen ve Dean, 1965), değişebilir $\mathrm{K}, \mathrm{Ca}$ ve $\mathrm{Mg} 1 \mathrm{~N}$ amonyum asetat (pH 7) metoduna göre (Kacar 2014), alınabilir $\mathrm{Fe}, \mathrm{Zn}, \mathrm{Cu}$ ve $\mathrm{Mn}$ DTPA metoduna göre (Lindsay ve Norvell 1978) belirlenmiştir.

Deneme toprağının killi tın bünyeye sahip olduğu, nötr karakterli, aşırı kireçli ve organik madde açısından orta seviyede olduğu tespit edilmiş, bununla birlikte tuzluluk problemi olmadığ $\breve{1}_{1}$ belirlenmiştir. Deneme toprağ (1990)'un sınır değerlerine göre değerlendirildiğinde; toplam $\mathrm{N}$ ve alınabilir $\mathrm{P}$ içeriklerinin iyi; değişebilir $\mathrm{Ca}$ ve $\mathrm{Mg}$ içeriklerinin yüksek; değişebilir $\mathrm{K}$ içeriğinin ise az olduğu tespit edilmiștir. Mikro element içerikleri bakımından ise; alınabilir $\mathrm{Fe}, \mathrm{Mn}$ ve $\mathrm{Cu}$ yönünden yeterli, alınabilir $\mathrm{Zn}$ yönünden ise noksanlık gösterebilir durumda olduğu belirlenmiştir. Deneme süresince; kontrol konuları periyodik olarak tartılarak, kullanılabilir su içeriği $\% 50$ azaldığında tüm saksılar tarla kapasitesine gelecek şekilde sulanmıștır. Deneme sonuçlarının istatistiksel değerlendirmeleri MINITAB ve MSTAT-C paket programları kullanılarak yapılmış, ortalamalar arası farklılıklar LSD testi ile araştırılmış ve farklı grupların harflendirilmesinde $\% 5$ önemlilik düzeyi esas alınmıştır.

\section{Bulgular ve Tartışma}

Farklı inkübasyon sürelerinde, toprağa artan düzeylerde uygulanan vermikompostun toprakların toplam $\mathrm{N}$, alınabilir $\mathrm{P}$, $\mathrm{Zn}, \mathrm{Fe}, \mathrm{Mn}, \mathrm{Cu}$, değişebilir $\mathrm{K}$ ve $\mathrm{Ca}$ içerikleri üzerine etkileri istatistiksel olarak \%0.1 düzeyinde önemli bulunmuş ve elde edilen sonuçlar Çizelge 2' de verilmiştir. Toprakların değişebilir $\mathrm{Mg}$ içeriği üzerine etkilerinin ise istatistiksel olarak önemsiz olduğu belirlenmiştir.

Toprağa yapılan vermikompost uygulamalarında, inkübasyon sürelerinin uzamasına bağlı olarak toprakların toplam N içeriğinin 30.güne doğru arttığ 60 .güne doğru azaldığı saptanmıştır. Toprakların en yüksek toplam $\mathrm{N}$ içeriğ $i$ 30. günde (\%0.126) elde edilmiştir (Çizelge 2). Holozlu (2013), toprağa $\% 16$ oranda yıkanmış mantar kompostu uygulamasının 
inkübasyona bağlı olarak örneklerin toplam $\mathrm{N}$ içeriğinde istatiksel olarak önemli artışlara sebep olduğunu belirtmiştir. Alagöz ve ark. (2006) yedi aylık inkübasyon süresi sonunda toprağa işlenmiş 100,200 ve $400 \mathrm{~kg} \mathrm{ha}^{-1}$ leonardit ve 1250 , 2500 ve $5000 \mathrm{~kg} \mathrm{ha}^{-1}$ çöp kompostu ve işlenmiş tavuk gübresi uygulamalarının toprağın toplam $\mathrm{N}$ içeriğini arttırdığını belirtmişlerdir. Zengin ve ark. (1999); sığır gübresi, tavuk gübresi ve üre gübresinin buğday anızı karıştırılmış toprağın mineralizasyonu ve $\mathrm{C}: \mathrm{N}$ oranı üzerine etkilerini incelemişlerdir. $25,50,75$ ve 100 . günlere doğru inkübasyon süresinin uzamasına bağlı olarak toprağın $\mathrm{NH}_{4}-\mathrm{N}$ ve $\mathrm{NO}_{3}-\mathrm{N}$ içeriğinin artış gösterdiğini, $\mathrm{C}: \mathrm{N}$ oranının ise, uzayan inkübasyon sürelerine bağlı olarak ilk olarak artış gösterip daha sonra ise belirli inkübasyon süresi sonunda azalış gösterdiğini tespit etmişlerdir.

Farklı inkübasyon dönemlerinde uygulanan vermikompostun; toprakların alınabilir $\mathrm{P}, \mathrm{Zn}, \mathrm{Fe}$ ve $\mathrm{Cu}$ içeriklerini 30.güne doğru azalttığı 60.güne doğru ise artırdığ1 tespit edilmiştir. İnkübasyon sürelerinin uzamasına bağlı olarak en yüksek alınabilir $\mathrm{P}, \mathrm{Zn}, \mathrm{Fe}$ ve $\mathrm{Cu}$ içerikleri 0 . günde (sırasiyla $6.10 \mathrm{ppm}, 0.14 \mathrm{ppm}, 8.77 \mathrm{ppm}$ ve $333 \mathrm{ppm}$ ) saptanmıştır (Çizelge 2). Sönmez ve ark. (2017a) toprağa uyguladıkları leonardit materyalinin inkübasyon dönemleri sonucunda DTPA-ekstrakte edilebilir Fe içeriğini arttırdığını, uyguladıkları leonardit dozlarının artmasıyla toprakların DTPAekstrakte edilebilir Fe içeriğinin önce azaldığını sonra arttığını saptamışlardır. Kara ve Erel (1999), artan tavuk gübresi dozlarına bağlı olarak, inkübasyonun 28. gününden sonra toprakların alınabilir $\mathrm{Cu}$ içeriğinin genel olarak azaldığını gözlemlemişlerdir.

Çizelge 2'den de görüldüğü üzere; vermikompost uygulamalarında, inkübasyon sürelerinin uzamasına bağlı olarak toprakların değişebilir $\mathrm{K}, \mathrm{Ca}$ ve alınabilir $\mathrm{Mn}$ içeriklerinin azaldığı belirlenmiştir. İnkübasyon sürelerinin uzamasına bağlı olarak en yüksek değişebilir K, Ca ve alınabilir Mn içerikleri 0 . günde (sırasiyla $79.17 \mathrm{ppm}, 8927.8 \mathrm{ppm}$ ve $10.96 \mathrm{ppm}$ ) elde edilmiştir. Bellitürk ve ark. (2009), inkübasyon sonrası toprakların $\mathrm{K}$ içerikleri ile mineralizasyon kapasiteleri arasında önemli ilişkiler bulamamıştır. Sönmez ve ark. (2017a) toprağa uyguladıkları leonardit materyalinin inkübasyon dönemleri sonucunda toprakların değişebilir $\mathrm{K}$ içeriğinin arttığını, ancak leonardit dozlarının artmasıyla toprakların değişebilir $\mathrm{K}$ içeriğinin değişmediğini belirtmişlerdir. Azarmi ve ark. (2008), domates yetiştirilen topraklarda dekara 1.5 ton vermikompost uygulandığında toprakların $\mathrm{Ca}$ miktarlarında artış olduğunu ifade etmişlerdir.

Vermikompost uygulamalarında, inkübasyon sürelerinin uzamasına bağlı olarak toprakların değişebilir $\mathrm{Mg}$ içerikleri değişmemiş ve istatistiksel olarak önemsiz bulunmuştur.

Artan dozlarda vermikompost uygulamalarının toprakların toplam $\mathrm{N}$, alınabilir $\mathrm{P}$, değiş̧ebilir $\mathrm{K}$ içerikleri üzerine etkileri istatistiksel olarak \%0.1; alınabilir $\mathrm{Zn}$ ve $\mathrm{Mn}$ içerikleri üzerine $\% 1$; değişebilir $\mathrm{Ca}$ içeriği üzerine etkisi $\% 5$ düzeyinde önemli bulunurken; toprakların değişebilir $\mathrm{Mg}$, alınabilir $\mathrm{Fe}$ ve $\mathrm{Cu}$ içerikleri üzerine etkileri istatistiksel olarak önemsiz bulunmuştur (Çizelge 3).

Çizelge 3 'den de görüldüğü üzere artan düzeyde yapılan vermikompost uygulamaları genel olarak toprakların toplam $\mathrm{N}$, alınabilir $\mathrm{P}, \mathrm{Zn}, \mathrm{Mn}$ ve değişebilir $\mathrm{K}$ içeriklerinin artışına neden olmuştur. Vermikompost uygulama dozuna bağlı olarak en yüksek toplam $\mathrm{N}$, değişsebilir $\mathrm{K}$ içerikleri $50 \mathrm{~kg} \mathrm{da}^{-1}$ uygulama dozunda (sirasiyla $\% 0.130$ ve $75.70 \mathrm{ppm}$ ) elde edilirken; en yüksek alınabilir P ve Zn içerikleri $100 \mathrm{~kg} \mathrm{da}^{-1}$ (sırasıyla 5.29 ppm ve 0.14 ppm), alınabilir Mn içeriği ise 7.89 ppm ile $200 \mathrm{~kg}$ $\mathrm{da}^{-1}$ uygulama dozunda saptanmıştır (Çizelge 3). Artan düzeyde yapılan vermikompost uygulamalarının genel olarak toprakların değişebilir $\mathrm{Ca}$ içeriklerinin azalmasına neden olduğu belirlenmiş ve en yükssek değişebilir Ca içeriği $50 \mathrm{~kg} \mathrm{da}^{-1}$ (8650.4 ppm) dozunda elde edilmiştir.

Sönmez ve ark. (2017b), artan dozlarda uygulanan mantar kompostu, leonardit ve tavuk gübresi uygulamalarının toprakların toplam $\mathrm{N}$ içeriklerinin genel olarak artmasına neden olduğunu belirtmişlerdir. Tamer ve ark.(2016), farklı dozlarda yapılan organik materyal ilavesinin toprakların $\mathrm{K}$ ve $\mathrm{P}$ içeriğ $i$ üzerine etkisinin istatistiksel olarak önemsiz olduğunu, ancak toplam $\mathrm{N}$ içeriğini artırdığını belirlemişlerdir. Ece ve ark. (2007), leonardit uygulamasının kontrol uygulamasına göre toprakların $\mathrm{N}$ içeriğini arttırdığını belirtmişlerdir. Azarmi ve ark. (2008), domates yetiştirilen topraklarda dekara 1.5 ton vermikompost uygulandığında toprakların $\mathrm{P}$ miktarlarında artış olduğunu ifade etmişlerdir. Kara (1997), artan tavuk gübresi dozlarına bağlı olarak toprakların $\mathrm{Zn}$ içeriklerinin arttığını belirtmiştir. Uz ve ark. (2016), ahır gübresi ve vermikompost uygulanan toprakların mikro element içeriklerinde kontrole göre ciddi artışlar olduğunu belirlemişlerdir. Çalışmamızda elde etmiş̧ olduğumuz bulgularımız literatürlerle paralellik göstermektedir.

Çizelge 2. Farklı inkübasyon dönemlerinin toprağın bitki besin element içeriğine etkisi ${ }^{1}$.

Table 2. Effects of different incubation times on nutrients contents of soils ${ }^{1}$.

\begin{tabular}{|c|c|c|c|c|}
\hline Toprak Parametreleri & 0. Gün & 30. Gün & 60. Gün & Önemlilik Düzeyi \\
\hline Toplam N (\%) & $0.117 \mathrm{~B}$ & $0.126 \mathrm{~A}$ & $0.114 \mathrm{~B}$ & $* * *$ \\
\hline Alınabilir P (ppm) & $6.10 \mathrm{~A}$ & $3.04 \mathrm{C}$ & $3.40 \mathrm{~B}$ & $* * *$ \\
\hline Değişebilir K (ppm) & $79.17 \mathrm{~A}$ & $75.97 \mathrm{~B}$ & $65.09 \mathrm{C}$ & $* * *$ \\
\hline Değişebilir Ca (ppm) & $8927.8 \mathrm{~A}$ & 8486 B & $8016.3 \mathrm{C}$ & $* * *$ \\
\hline Değişebilir Mg (ppm) & 982.3 & 930.0 & 1056.4 & öd \\
\hline Alınabilir Zn (ppm) & $0.14 \mathrm{~A}$ & $0.091 \mathrm{C}$ & $0.18 \mathrm{~B}$ & $* * *$ \\
\hline Alınabilir Fe (ppm) & $8.77 \mathrm{~A}$ & $4.28 \mathrm{C}$ & $5.26 \mathrm{~B}$ & $* * *$ \\
\hline Alınabilir Mn (ppm) & $10.96 \mathrm{~A}$ & $5.54 \mathrm{~B}$ & $5.60 \mathrm{~B}$ & $* * *$ \\
\hline Alınabilir Cu (ppm) & $3.33 \mathrm{~A}$ & $2.54 \mathrm{C}$ & $2.82 \mathrm{~B}$ & $* * *$ \\
\hline
\end{tabular}

${ }^{1}$ Değerler 3 tekerrür ortalamasıdır. 
Çizelge 3. Artan dozlarda yapılan vermikompost uygulamalarının toprağın bitki besin element içeriği üzerine etkisi ${ }^{1}$.

Table 3. Effects of increasing vermicompost application on the nutrients contents of soils ${ }^{1}$.

\begin{tabular}{|c|c|c|c|c|c|}
\hline \multirow[t]{2}{*}{ Toprak Parametreleri } & \multicolumn{4}{|c|}{ Gübre Dozları $\left(\mathrm{kg} \mathrm{da}^{-1}\right)$} & \multirow[t]{2}{*}{ Önemlilik Düzeyi } \\
\hline & $\mathbf{0}$ & 50 & 100 & 200 & \\
\hline Toplam N (\%) & $0.103 \mathrm{C}$ & $0.130 \mathrm{~A}$ & $0.121 \mathrm{~B}$ & $0.123 \mathrm{~B}$ & $* * *$ \\
\hline Alınabilir P (ppm) & $2.09 \mathrm{C}$ & $4.06 \mathrm{~B}$ & $5.29 \mathrm{~A}$ & $5.28 \mathrm{~A}$ & $* * *$ \\
\hline Değişebilir K (ppm) & $69.72 \mathrm{~B}$ & $75.70 \mathrm{~A}$ & $74.51 \mathrm{~A}$ & $73.72 \mathrm{~A}$ & $* * *$ \\
\hline Değişebilir Ca (ppm) & $8610.4 \mathrm{~A}$ & $8650.4 \mathrm{~A}$ & $8611.6 \mathrm{~A}$ & $8034.4 \mathrm{~B}$ & $*$ \\
\hline Değişebilir Mg (ppm) & 1051.8 & 985.9 & 886.6 & 1034.0 & öd \\
\hline Alınabilir Zn (ppm) & $0.11 \mathrm{~B}$ & $0.11 \mathrm{~B}$ & $0.14 \mathrm{~A}$ & $0.11 \mathrm{~B}$ & $* *$ \\
\hline Alınabilir Fe (ppm) & 5.95 & 6.04 & 5.97 & 6.07 & öd \\
\hline Alınabilir Mn (ppm) & $7.52 \mathrm{BA}$ & $7.11 \mathrm{BC}$ & $6.94 \mathrm{C}$ & $7.89 \mathrm{~A}$ & $* *$ \\
\hline Alınabilir $\mathrm{Cu}$ (ppm) & 2.86 & 2.83 & 2.862 & 3.04 & öd \\
\hline
\end{tabular}

${ }^{1}$ Değerler 3 tekerrür ortalamasıdır.

Çizelge 3'den de görüldüğ̈ü gibi; artan düzeyde yapılan vermikompost uygulamalarının toprakların değişebilir $\mathrm{Mg}$, alınabilir $\mathrm{Fe}$ ve $\mathrm{Cu}$ içerikleri üzerine etkisi istatistiksel olarak önemsiz bulunmuştur. Güneş (2007) organik ve mineral gübre uygulamalarının etkilerini araştırdıkları çalışmalarında, leonardit uygulamalarının toprakların makro besin elementleri içeriklerinde genel olarak artışlara neden olduğunu saptamışlardır. Yılmaz ve Alagöz (2009), organik materyal olarak meyve suyu fabrikası atıklarından elde edilen elma posasını (EP), killi tekstüre sahip toprağa uygulamışlar ve elma posası uygulamasıyla toprakların toplam N, alınabilir $\mathrm{P}, \mathrm{Fe}, \mathrm{Mn}$ ve $\mathrm{Cu}$ içeriklerinde önemli artışların olduğunu belirtmiş̧lerdir. Çıtak ve ark. (2011), düşük dozlarda bile olsa vermikompost uygulamalarının toprakların $\mathrm{Cu}$ kapsamlarına olumlu etki gösterdiğini belirtmişlerdir.

\section{Sonuç}

Araştırma sonucunda; inkübasyon süresinin uzamasına (60. güne doğru) bağlı olarak toprakların değişebilir $\mathrm{K}, \mathrm{Ca}$ ve alınabilir Mn içeriklerinin azaldığı tespit edilmiştir. Toprakların alınabilir $\mathrm{P}, \mathrm{Zn}, \mathrm{Fe}$ ve $\mathrm{Cu}$ içeriklerinin 30.güne doğru azaldığı; 60. günde arttığ 1 ; toprakların toplam $\mathrm{N}$ içeriğinin ise 30 . güne kadar arttığı ancak 60 . günde azaldığı belirlenmiştir. Toprakların değişebilir $\mathrm{Mg}$ içeriği üzerine ise inkübasyon süresinin etkisi önemsiz bulunmuştur.

Artan vermikompost uygulama dozuna bağlı olarak ise toprakların toplam $\mathrm{N}$, alınabilir $\mathrm{P}, \mathrm{Zn}, \mathrm{Mn}$ ve değişebilir $\mathrm{K}$ içeriklerinin genel olarak arttığı; değişebilir $\mathrm{Ca}$ içeriğinin azaldığı belirlenmiştir. Toprakların alınabilir $\mathrm{Fe}, \mathrm{Cu}$ ve değişebilir $\mathrm{Mg}$ içerikleri üzerine vermikompost uygulama dozlarının etkisi ise önemsiz bulunmuştur.

Sonuç olarak farklı inkübasyon dönemlerine ve artan vermikompost uygulama dozlarına bağlı olarak toprakların bitki besin element içeriklerinin birbirlerinden farklılık gösterdiği; inkübasyon süresinin uzamasına bağlı olarak bitki besin elementi içeriklerinin genel olarak azaldığı, artan vermikompost uygulamalarına bağlı olarak ise arttığı belirlenmiştir.

\section{Kaynaklar}

Alagöz Z, Yılmaz E, Öktüren F (2006) Organik materyal ilavesinin bazı fiziksel ve kimyasal toprak özellikleri üzerine etkileri. Akdeniz Üniversitesi Ziraat Fakültesi Dergisi 19(2): 245-254.
Ansari AA (2008) Effect of vermicompost on the productivity of potato (Solanum tuberosum), spinach (Spinacia Oleracea) and turnip (Brassica campestris). World J. of Agric. Sci. 4(3): 333-336.

Azarmi R, Giglou MT, Talesmikail RD (2008) Influence of vermicompost on soil chemical and physical properties in tomato (Lycopersicum Esculentum) field. African Journal of Biotechnology 7(14): 2397-2401.

Bellitürk K, Sağlam M.T (2005) Tekirdağ ili topraklarının mineralize olan azot miktarları ile mineralizasyon kapasiteleri üzerinde bir araştırma. Tekirdağ Ziraat Fakültesi Dergisi Cilt 2(1): 89-101.

Bellitürk K, Danışman F, Sözübek B (2009) Tekirdağ yöresindeki toprakların bazı fiziksel ve kimyasal özellikleri ile mineralizasyon kapasiteleri arasındaki ilişkiler. Akdeniz Üniversitesi Ziraat Fakültesi Dergisi 22(2): 141-147.

Çıtak S, Sönmez S, Koçak F, Yaşin S (2011) Vermikompost ve ahır gübresi uygulamalarının ispanak (Spinacia Oleracea var. 1.) bitkisinin gelişimi ve toprak verimliliği üzerine etkileri. Batı Akdeniz Tarımsal Araştırma Enstitüsü Derim Dergisi 28(1): 56-69.

Ece A, Saltalı K, Eryiğit N, Uysal F (2007) The effects of leonardite applications on climbing bean (Phaseolus vulgaris L.) yield and the some soil properties. Journal of Agronomy 6(3): 480-483.

Eczacıbaşı B, Arcak S (1999) Islah Edilmiş topraklarda tarımsal atıkların azot mineralizasyonu ve bazı toprak özellikleri üzerine etkileri. Master Tezi, (Yayınlanmamış). A. Ü. Fen Bil. Enstitüsü, Ankara.

FAO (1990) Micronutrient, assesment at the country level: An International study. FAO Soil Bulletin 63, Rome.

Garg VK, Gupta R, Yadav A (2010) Vermicomposting technology for solid waste management. http://www.environmentolexpert.com/Files/0/articles/9047/.

Vermicomposting_article_for_the_biofertilizer_people.pdf. Erişim 26 Nisan 2015.

Güneş A (2007) Allüviyal materyaller üzerinde oluşan topraklarda yetiştirilen mısır bitkisinin (zea mays 1) verim ve besin içeriği üzerine organik ve mineral gübre uygulamalarının etkisi. Atatürk Üniversitesi Fen Bilimleri Enstitüsü Toprak Anabilim Dalı yüksek lisans tezi. Erzurum.

Holozlu A (2013) Yıkanmış ve yıkanmamış atık mantar kompostunun bazı toprak kalite parametrelerine etkisi. Selçuk Üniversitesi Fen Bilimleri Enstitüsü. Yüksek Lisans Tezi.

Jackson MC (1967) Soil chemical analysis. Prentice Hall of India Private'Limited, New Delhi.

Jakse M, Mihelic R (1999) The influence of organic and mineral fertilisation on vegetable growth and $\mathrm{N}$ availability in soil. Preliminary results. Acta Horticulturae 506: 69-75. 
Kacar B, İnal A (2010) Bitki analizleri. Nobel Akademik Yayınları.

Kacar B (2014) Toprak Analizleri. Nobel Akademik Yayınları (3. Bask1).

Kara EE (1997) Gelemen tarım işletmesindeki toprak serilerinde, inkübasyon süresine bağlı olarak bazı mikrobiyolojik özelliklerinde meydana gelen değişmeler. Tr. J. of Agriculture and Forestry 23 Ek Say1 2, 459-466.

Kara E, Erel A (1999) Tavuk gübresinin bazı toprak özelliklerine ve yulaf kuru bitki ağırlığına etkisi. Anadolu, J. of AARI 9(2): 91-104.

Lindsay WL, Norvell WA (1978) Development of a DTPA soil test for zinc, iron, manganese and copper. Soil Sci. Amer. Jour. 42(3): 421 428. Madisson, Wilconsin, USA, 1372-1376.

Olsen SR, Dean LA (1965) Phosphorus (Ed. C. A. Black) methods of soil analysis. Part 2. American Society of Agronomy. Inc. Publisher Madison Wisconsin USA, 1035-1049.

Sönmez S, Özen N, Kılıç E (2017a) Farklı inkübasyon dönemlerinde uygulanan leonarditin toprağın verimliliği üzerine etkileri. 5 . Uluslararası Katılımlı Toprak ve $\mathrm{Su}$ Kaynakları Kongresi, Kirklareli, Cilt- 2. s. 986- 995.

Sönmez S, Kılıç E, Özen N (2017b) Farklı Organik materyallerin azot mineralizasyon oranlarının karşılaştırılması. 5. Uluslararası
Katılımlı Toprak ve Su Kaynakları Kongresi, Kırklareli, Cilt-2. s. 979-985.

Tamer N, Başalma D, Türkmen C, Namlı A (2016). Organik toprak düzenleyicilerin toprak parametreleri ve ayçiçeği (Helianthus annuus L.) bitkisinin verim ve verim öğeleri üzerine etkileri. Toprak Bilimi ve Bitki Besleme Dergisi 4(1): 11-21.

Uz İ, Sönmez S, Tavali İE, Citak S, Üras DS, Çitak S (2016) Effect of vermicompost on chemical and biological properties of an alkaline soil with high lime content during celery (Apium graveolens L. var. dulce Mill.) production. Notulae Botanicae Hortı Agrobotanıcı Cluj-Napoca 44: 280-290.

Yılmaz E, Alagöz Z (2009) Organik materyal (elma posası) uygulamasının toprağın bazı verimlilik özelliklerine etkisi. Akdeniz Üniversitesi Ziraat Fakültesi Dergisi 22(2): 233-250.

Wadman WP, De Haan S (1997) Decomposition of organic matter from 36 soils in a long-term pot experiment. Plant and Soil 189: 289-301.

Zengin M, Şeker C, Uyanöz R (1999) Buğday anızı karıştırılmış toprağın azot mineralizasyonu ve $\mathrm{C}: \mathrm{N}$ oranı üzerine bazı organik gübreler ile üre gübresinin etkileri. Selçuk Üniv. Ziraat Fakültesi Dergisi 13(20): 1-9. 